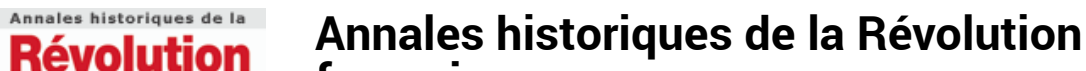

française française

358 | octobre-décembre 2009

Varia

\section{Blaise BACHOFEN et Céline SPECTOR (dir.), Principes $d u$ droit de la guerre - Écrits sur la paix perpétuelle}

Paris, Vrin, 2008, 342 p., ISBN 978-2-7116-2141-5, $34 €$

\section{Marc Belissa}

\section{(2) OpenEdition}

\section{Journals}

Édition électronique

URL : https://journals.openedition.org/ahrf/11577

DOI : 10.4000/ahrf.11577

ISSN : 1952-403X

Éditeur :

Armand Colin, Société des études robespierristes

\section{Édition imprimée}

Date de publication : 1 octobre 2009

Pagination : 190-191

ISBN : 978-2-200-92560-4

ISSN : 0003-4436

Référence électronique

Marc Belissa, « Blaise вAchofen et Céline spector (dir.), Principes du droit de la guerre - Écrits sur la paix perpétuelle", Annales historiques de la Révolution française [En ligne], 358 | octobre-décembre 2009, mis en ligne le 29 juillet 2010, consulté le 23 avril 2022. URL : http://journals.openedition.org/ahrf/11577 ; DOl : https://doi.org/10.4000/ahrf.11577

Ce document a été généré automatiquement le 23 avril 2022.

Tous droits réservés 


\title{
Blaise BACHOFEN et Céline SPECTOR (dir.), Principes du droit de la guerre - Écrits sur la paix perpétuelle
}

Paris, Vrin, 2008, 342 p., ISBN 978-2-7116-2141-5, $34 €$

\author{
Marc Belissa
}

\section{RÉFÉRENCE}

Blaise BACHOFEN et Céline SPECTOR (dir.), Principes du droit de la guerre - Écrits sur la paix perpétuelle, Paris, Vrin, 2008, 342 p., ISBN 978-2-7116-2141-5, $34 €$

Une nouvelle édition des textes de Rousseau sur la guerre et la paix vient de paraitre chez Vrin sous la direction de Blaise Bachofen et de Céline Spector. L'originalité de cette publication est la reconstruction proposée des «Principes du droit de la guerre » jusque-là édités sous la forme de fragments sans lien entre eux. Les textes présentés ici ne sont donc pas «inédits" à proprement parler, mais cette édition leur donne une nouvelle cohérence et elle éclaire d'un jour nouveau le projet des "Institutions politiques » de Rousseau, comme ses textes de et sur l'abbé de Saint-Pierre. Ce corpus comprend d'une part les «Principes du droit de la guerre » et les «Fragments sur la guerre " tels qu'ils apparaissent dans les manuscrits, puis d'autre part une version "mise au net» des "Principes du droit de la guerre», aboutissant ainsi à un «nouveau » texte de Rousseau. Suivent «L'Extrait de Projet de paix perpétuelle de M. de l'abbé de Saint-Pierre » et le "Jugement sur la paix perpétuelle». Le corpus est accompagné de quatre commentaires substantiels.

2 L'ouvrage est introduit par Céline Spector et Blaise Bachofen qui posent la question du rapport de l'œuvre de Rousseau avec la problématique de la guerre et de la paix. Il s'agit pour les auteurs de présenter comment Rousseau conçoit l'origine de la guerre et de la justice dans la guerre et comment il envisage le problème de la construction de la paix par la confédération. Bruno Bernardi et Gabriella Silvestri présentent ensuite 
l'édition elle-même et la méthode suivie dans la reconstruction des Principes du droit de la guerre. Les commentaires qui suivent l'édition sont autant de jalons importants dans l'étude de l'œuvre de Rousseau sur la guerre et la paix. Blaise Bachofen nous montre que l'œuvre de Rousseau « délivre des enseignements cruciaux pour notre temps » et affaiblit les "accusations d'irréalisme " souvent adressées à sa philosophie politique. Florence Guénard propose ensuite une étude intitulée « Puissance et amour de soi » qui reprend la question sous l'angle de la théorie de l'homme chez Rousseau. La guerre n'est pas le fruit de sa méchanceté des hommes mais de la "politique » des États. Céline Spector décrit ensuite les rapports entre les textes de l'abbé de Saint-Pierre et ceux de Rousseau et démontre de manière convaincante que ce n'est pas la proposition faite à Rousseau d'éditer un abrégé des œuvres de l'abbé qui a provoqué chez lui l'interrogation sur la guerre et la paix. Celle-ci précède largement ce travail d'édition. Par ailleurs, Céline Spector analyse la manière dont Rousseau tente de contourner l'accusation « d'utopisme » accolée au Projet de l'abbé de Saint-Pierre. Enfin, la dernière contribution de Bruno Bernardi s'intéresse à l'idée de société civile européenne chez Rousseau et par conséquent au concept de confédération des peuples pour sortir de l'état de guerre et construire la paix.

3 Cette édition tout à fait originale et importante des textes de Rousseau sur la guerre modifie considérablement la manière dont on doit envisager la place de cette thématique dans sa pensée politique. Les études qui l'accompagnent viennent heureusement compléter la bibliographie - assez peu importante - déjà existante sur cette question que l'on trouvera à la fin de l'ouvrage. 